need to be addressed by academic departments of family medicine led to a lengthy and active question/ answer period that concluded the session!

ADFM has many collaborative partnerships and priority initiatives that generated other plenaries. The Best Practice Guide for Strategic Planning to Increase Student Choice of Family Medicine made its soft launch debut at the 2020 Annual Conference. It was developed by ADFM's Education Transformation Committee with feedback and support from several FM associations and the 25x2030 Student Choice Collaborative. Building Research Capacity (BRC) is a joint initiative between ADFM and NAPCRG in cooperation with STFM and AFMRD. BRC held their very first preconference workshop, The Leader's Guide to Decision-Making When Building Research and Scholarship Capacity and also facilitated the ABFM Updates and Opportunities for Research Partnership-Working Together presentation by ABFM President \& CEO, Warren Newton, MD, $\mathrm{MPH}$. Development of leadership skills and the theme of having critical conversations was addressed by the Leader Development Committee's Conflict Management 301 preconference workshop; How Departments Can Engage in Respectful Dialogue in an Era of Diverse Values, session moderated by Christine Arenson, MD, with a panel of Kevin Grumbach, MD, Julie Moretz, and Thomas Peterson, $\mathrm{MD}_{i}$ and the Leadership \& Management Dilemmas Dinner moderated by Jeff Borkan, MD, PhD, Thomas Peterson, MD, and Steven Rothschild, MD.

The business of running a department is always covered in numerous ways at the ADFM conference. This year, it was addressed by The Changing Landscape of Reimbursement: Challenges and Opportunities moderated by Kim Roe, MBA, with a panel of Norman Ward, MD, David Serlin, MD, Jeff Borkan, MD, PhDi The 'Unproductive Provider': A Systematic Method for Evaluation and Improvement of Under-Producing Physicians and Advance Practice Nurses presented by C. Kimi Suh, MD, MPH, FAAFP, Karen Tate, MPH, Aaron J. Michelfelder, MD, FAAFP, FAAMA; and Communication in a Complex Family Medicine Department presented by James Pacala, MD, MS.

Overall, something of interest for all attendees with some fun thrown in-a party to celebrate Emeritus Executive Director Ardis Davis on Thursday night and yoga led by our own Reid Blackwelder, MD, on Friday morning. Not to mention pre-Mardi Gras parades around the hotel that added a beat and spectacle each night. Now, on to Atlanta (Buckhead) for the 2021 Annual Conference!

Susan Latta

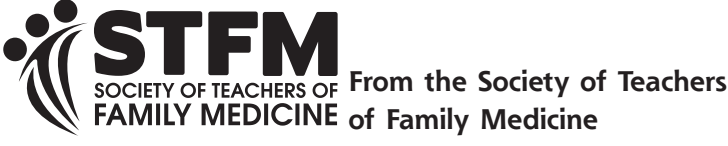

Ann Fam Med 2020;18:285-286. https://doi.org/10.1370/afm.2549.

\section{STFM FORMS TASK FORCE TO DEVELOP A NATIONAL TELEMEDICINE CURRICULUM}

Telemedicine or telehealth-defined as the longdistance delivery of medical care using technologyhas grown exponentially in the United States in the past 20 years, and contemporary trends in the health care environment are serving to fuel this growth into the future. More than one-half of all US health care institutions provide some form of telemedicine, and more are employing increasingly sophisticated tools. ${ }^{1-3}$ Undoubtedly, the COVID-19 pandemic has quickly escalated this need in the first half of 2020.

\footnotetext{
"When all is said and done, the COVID-19 pandemic will likely be seen as a tipping point for telemedicine in the United States. Telemedicine has been indispensable in delivering care to patients sheltered at home, while minimizing risks to providers. Prior to COVID-19, only $28 \%$ of US physicians were using telemedicine; today it is the preferred, if not dominant, method of delivering care in a time of crisis. Yet, there remains no widely recognized gold standard for telemedicine training for medical students and residents. What we need now is a national telemedicine curriculum to be developed and taught in medical schools and residencies across the country," said STFM Telemedicine Task Force Chair Steven Lin, MD.
}

Telemedicine is associated with better patient access (especially in underserved and rural areas), decreased health care costs, high patient and provider satisfaction, and equal or better patient outcomes for selected conditions compared with in-person care. ${ }^{4}$

One of the biggest barriers to telemedicine adoption is lack of provider training. A 2017 survey of nearly 5,000 family physicians found that, despite considerable interest, only $15 \%$ of respondents were using telemedicine, $55 \%$ cited lack of training as their reason for not using it. ${ }^{5}$ The AMA and AAMC have called for telemedicine to become a core competency of medical students and residents. ${ }^{6.7}$ According to AAMC and LCME, approximately 80 medical schools (about $50 \%-60 \%)$ currently include telemedicine as a topic in required or elective courses. ${ }^{8-9}$ There is a lack of data on how many residency programs provide telemedicine training. There is no widely recognized gold standard for telemedicine training for undergraduate or graduate medical education. A handful of institutions have described courses or parts of courses/clerkships that 
provide telemedicine training. These experiences offer insight into emerging best practices for a potential national curriculum.

At its December 2019 meeting, the STFM Board of Directors discussed the current state of telemedicine training in US medical schools, residency programs, and teaching hospitals, and approved the formation of a Telemedicine Curriculum Task Force to develop a national telemedicine curriculum for students, residents, and faculty that will include an organized repository of resources representing foundational topics and best practices in telemedicine, including but not limited to the following: modules, videos, case-based presentations, facilitators' guides, quizzes, OSCEs, etc.

The curriculum will be designed to help faculty integrate telemedicine topics into courses, clerkships, and residency curricula. The same content can also help students, residents, and faculty at institutions without such resources to obtain the skills needed to deliver telemedicine care in their practices. Because technology changes rapidly, the curriculum will be easily modifiable and not focus on specific technologies. The curriculum will:

- Provide strategies for integrating telemedicine into the clinical workflow

- Specifically address needs in rural and other underserved areas

- Include a guideline for integrating telemedicine into clinical practice. The guideline will be free and open access

"The task force is made up of telemedicine pioneers, change leaders, content experts, and key stakeholders from a diverse group of organizations, including the AAFP, VA, large health delivery systems, and academic medical centers that are driving the nation's telemedicine education innovations," said Dr Lin.

The STFM Telemedicine Curriculum Task Force members include:

- Steven Lin, MD, Stanford University

- Rika Bajra, MD, Stanford University

- Tom Banning, Texas Academy of Family Physicians

- Lance Fuchs, MD, Kaiser Permanente San Diego Family Medicine Residency

- Kevin Galpin, MD, Veterans Health Administration

- Bonnie Jortberg, PhD, RD, CDE, University of Colorado

- Mahesh Patel, MD, University of Illinois, Chicago

- Kerry Palakanis, DNP, APRN, Connect Care Operations, Murray, UT
- David Rakel, MD, University of New Mexico

- Scott Shipman, MD, Association of American Medical Colleges

- Steven Waldren, MD, American Academy of Family Physicians

- Mary Theobald, MBA, Society of Teachers of Family Medicine, Leawood, KS

The STFM Telemedicine Curriculum Task Force will complete its work in 2020-2021 with a curriculum launch scheduled for Fall of 2021. STFM will promote the curriculum and guideline through papers, peerreviewed journals, and presentations at the STFM Annual Spring Conference, the STFM Conference on Practice and Quality Improvement, the STFM Conference on Medical Student Educations, the AAFP Program Directors' Workshop, and the AAFP National Conference.

$$
\text { Mary Theobald, MBA and Traci Brazelton, CAE }
$$

\section{References}

1. Office of the Assistant Secretary for Planning and Evaluation. Report to Congress: e-health and telemedicine. Washington, DC: US Department of Health and Human Services. https://aspe.hhs.gov/ system/files/pdf/206751/TelemedicineE-HealthReport.pdf. Published Aug 19, 2016. Accessed Oct 10, 2019.

2. Foley $\varepsilon$ Lardner. 2017 telemedicine and digital health survey. https://www.foley.com/files/uploads/2017-Telemedicine-SurveyReport-11-8-17.pdf. Accessed Oct 10, 2019

3. Pathipati AS, Azad TD, Jethwani K. Telemedical education: training digital natives in telemedicine. J Med Internet Res. 2016;18(7):e193.

4. Dorsey ER, Topol EJ. State of telehealth. N Engl J Med. 2016;375(2): 154-161.

5. Moore MA, Coffman M, Jetty A, Klink K, Petterson S, Bazemore A. Family physicians report considerable interest in, but limited use of, telehealth services. J Am Board Fam Med. 2017;30(3):320-330.

6. American Medical Association. AMA encourages telemedicine training for medical students, residents. Published Jun 15, 2016. Accessed Oct 10, 2019. https://www.ama-assn.org/ press-center/press-releases/amaencouragestelemedicine-

7. Warshaw R. From bedside to webside: future doctors learn how to practice remotely. Association of American Medical Colleges. https://www.aamc.org/newsinsights/bedside-webside-future-doctorslearn-how-practice-remotely. Published Apr 24, 2018. Accessed Oct 10, 2019.

8. Association of American Medical Colleges. Content documentation in required courses and elective courses. https://www.aamc. org/data-reports/curriculum-reports/interactivedata/contentdocumentation-required-courses-and-elective-courses. Accessed Oct $10,2019$.

9. Waseh S, Dicker AP. Telemedicine training in undergraduate medical education: mixed-methods review. JMIR Med Educ. 2019;5(1): e12515. 